Article

\title{
Direct Evidence of Salinity and pH Effects on the Interfacial Interactions of Asphaltene-Brine-Silica Systems
}

\author{
Fanghui Liu ${ }^{1,2}$, Hui Yang ${ }^{1, * \mathbb{C}}$, Ting Chen ${ }^{1}$, Shanmeiyu Zhang ${ }^{1}$, Danfeng $\mathrm{Yu}^{3}$, \\ Yongqiang Chen ${ }^{4}$ and Quan Xie ${ }^{4, *}$ \\ 1 CAS Key Lab of Colloid, Interface and Chemical Thermodynamics, Institute of Chemistry, Chinese Academy \\ of Sciences, Beijing 100190, China; liufanghui@iccas.ac.cn (F.L.); chenting417@iccas.ac.cn (T.C.); \\ zhangsmy@iccas.ac.cn (S.Z.) \\ 2 University of Chinese Academy of Sciences, Beijing 100049, China \\ 3 School of Chemistry and Chemical Engineering, Guangzhou University, Guangzhou 510006, China; \\ ccyudanfeng@gzhu.edu.cn \\ 4 Department of Petroleum Engineering, Curtin University, Kensington 6151, Western Australia, Australia; \\ yongqiang.chen@postgrad.curtin.edu.au \\ * Correspondence: yanghui@iccas.ac.cn (H.Y.); quan.xie@curtin.edu.au (Q.X.); \\ Tel./Fax: +86-10-6252-3395 (H.Y.)
}

Received: 11 February 2020; Accepted: 6 March 2020; Published: 8 March 2020

check for updates

\begin{abstract}
The hydraulic fracturing technique remains essential to unlock fossil fuel from shale oil reservoirs. However, water imbibed by shale during hydraulic fracturing triggers environmental and technical challenges due to the low flowback water recovery. While it appears that the imbibition of fracturing fluid is a complex function of physico-chemical processes in particular capillary force which is associated with wettability of oil-brine-shale, the controlling factor(s) to govern the wettability is incomplete and the literature data in this context is missing. We thus measured the adsorption/desorption of asphaltenes on silica surface in the presence of brines using quartz crystal microbalance with dissipation (QCM-D). We detected zeta potential of asphaltene-brine and brine-silica systems and calculated the disjoining pressures of the asphaltene-brine-silica system in the case of different salinity. Moreover, we performed a geochemical study to quantify the variation of surface chemical species at asphaltene and silica surfaces with different $\mathrm{pH}$ values and used the chemical force microscope (CFM) method to quantify the effect of $\mathrm{pH}$ on intermolecular forces. Our results show that lowering salinity or raising $\mathrm{pH}$ reduced the adhesion force between asphaltene and silica surface. For example, at a pH value of 6.5 , when the concentration of injected water is reduced from $1000 \mathrm{mM}$ to $100 \mathrm{mM}$ and $10 \mathrm{mM}$, the adhesion force decreased by approximately $58 \%$ and $66 \%$, respectively. In addition, for the $100 \mathrm{mM} \mathrm{NaCl}$ solution, when the $\mathrm{pH}$ value increased from 4.5 to 6.5 and 9 , the adhesion force decreased by approximately $56 \%$ and $87 \%$, respectively. Decreased adhesion forces between asphaltene and the silica surface could promote the desorption of asphaltene from the silica surface, resulting in a negative zeta potential for both asphaltene-silica and brine-silica interfaces and a shift of wettability towards water-wet characteristic. During such a process, $-\mathrm{NH}^{+}$number at asphaltene surfaces decreases and the bonds between $-\mathrm{NH}^{+}$and $>\mathrm{SiO}^{-}$break down, to further interpret the formation of a thinner asphaltene adlayer on the rock surface. This study proposes a reliable theoretical basis for the application of hydraulic fracturing technology, and a facile and possible manipulation strategy to increase flowback water from unconventional reservoirs.
\end{abstract}

Keywords: salinity and $\mathrm{pH}$ effects; interfacial interactions; asphaltene adsorption/deposition; surface wettability; surface complexation modelling 


\section{Introduction}

Low emission energy is an indispensable resource in modern society and, therefore, both crude oil and natural gas resources are rapidly expanding to cope with the global growing energy needs $[1,2]$. The decline in conventional oil reserves has aroused great attention and transferred widespread interest into unconventional reservoirs, such as low permeability in a range of 1 to 1000 nano-darcy [3]. To economically unlock the oil and gas resources from such reservoirs, hydraulic fracturing needs to be implemented to extend the fracture network and activate new fractures, resulting in the enhancement of connectivity. However, $\sim 70 \%$ of fracturing fluids are often difficult to recover during a hydraulic fracturing process $[3,4]$, especially for the asphaltene-rich shale reservoirs, which received widespread attention in both technical and environmental fields. Various work has been implemented to understand why shale reservoirs yield low flowback water recovery during hydraulic fracturing, e.g., the imbibition of fracturing fluid on shale matrix and micro-fractures [5-7], the hydration of clay minerals [8,9], and the reduced permeability [10-12]. A generally accepted theory believed that during fracturing fluid injection, water will not imbibe into the hydrophobic matrix but will preferentially enter the hydrophilic micro-fractures and result in a low fracturing fluid recovery [13-15]. Thus, the oil recovery in low permeability oil reservoirs depends critically on the wetting properties of the shale matrix. It is important to explore the wettability alteration mechanism in improving oil recovery, especially to find an effective method to improve the wetting property of reservoir surfaces. In previous reports, a series of contact angles on shale samples were measured with aqueous ionic solutions at different concentrations, indicating that the shale had a higher affinity for more diluted solutions [16]. Some other experimental results show that the presence of divalent cations can significantly increase surface wettability compared to monovalent cations [2,17]. In addition, there are related studies claiming that ion type and strength significantly affect the wettability of the oil-brine-rock system, but the results were mostly obtained from macroscopic changes such as contact angle and interfacial tension [18-20]. Therefore, quantitative research and responsible mechanisms for wettability alteration are a great need.

To provide such a framework, we examined the adsorption/desorption of asphaltene on silica surface in the presence of $\mathrm{NaCl}$ aqueous solutions at a series of concentrations using the quartz crystal microbalance with dissipation (QCM-D) method and investigated the role of water uptake during these processes as well as wettability alteration. Based on such QCM-D results and our previous analysis of asphaltene desorption [18], we also used chemical force microscope (CFM) technology to directly measure the interaction between asphaltene and silica surface, and combined it with the Derjaguin-Landau-Verwey-Overbeek (DLVO) theory and surface complexation modelling to further delineate the interfacial interactions.

\section{Results and Discussion}

\subsection{Effect of Salinity on Adsorption/Desorption of Asphaltene on Silica Surface}

Figure 1 shows the frequency and dissipation variation during the asphaltene injection, pure solvent rinsing, and brine injection. F3, F5, F7 and D3, D5, D7 represent the frequency and dissipation curves corresponding to different overtones, respectively. When the frequencies and dissipation curves under different overtones coincide, it means that a rigid adsorption layer is formed. On the other hand, if they do not overlap, it means that the formed adsorption layer is loose. Resonance frequency represents the information of the adsorbed mass on surface, and energy dissipation provides the information of the elastic property of the adsorbed film, from which frequency decrease means asphaltene adsorption and dissipation increase means loose adsorption conformation. [21,22]. A decrease of $25-35 \mathrm{~Hz}$ in frequency and an increase of $2-3 \times 10^{-6}$ in dissipation are obtained due to the asphaltene adsorption in all cases, indicating the reproducibility and credibility. Negligible variations of frequency and dissipation values at different overtones are also found during the injection of asphaltene, indicating the formation of rigid films in line with previous reports $[12,23]$. After the adsorption equilibrium, the surface is rinsed by pure solvent toluene, and then the aqueous solution is introduced which triggers sharp changes in 
both frequency and dissipation, in the formation of swelling adlayers. This is largely due to the liquid loading effect as a result of differences in viscosity and density between toluene and water [24].
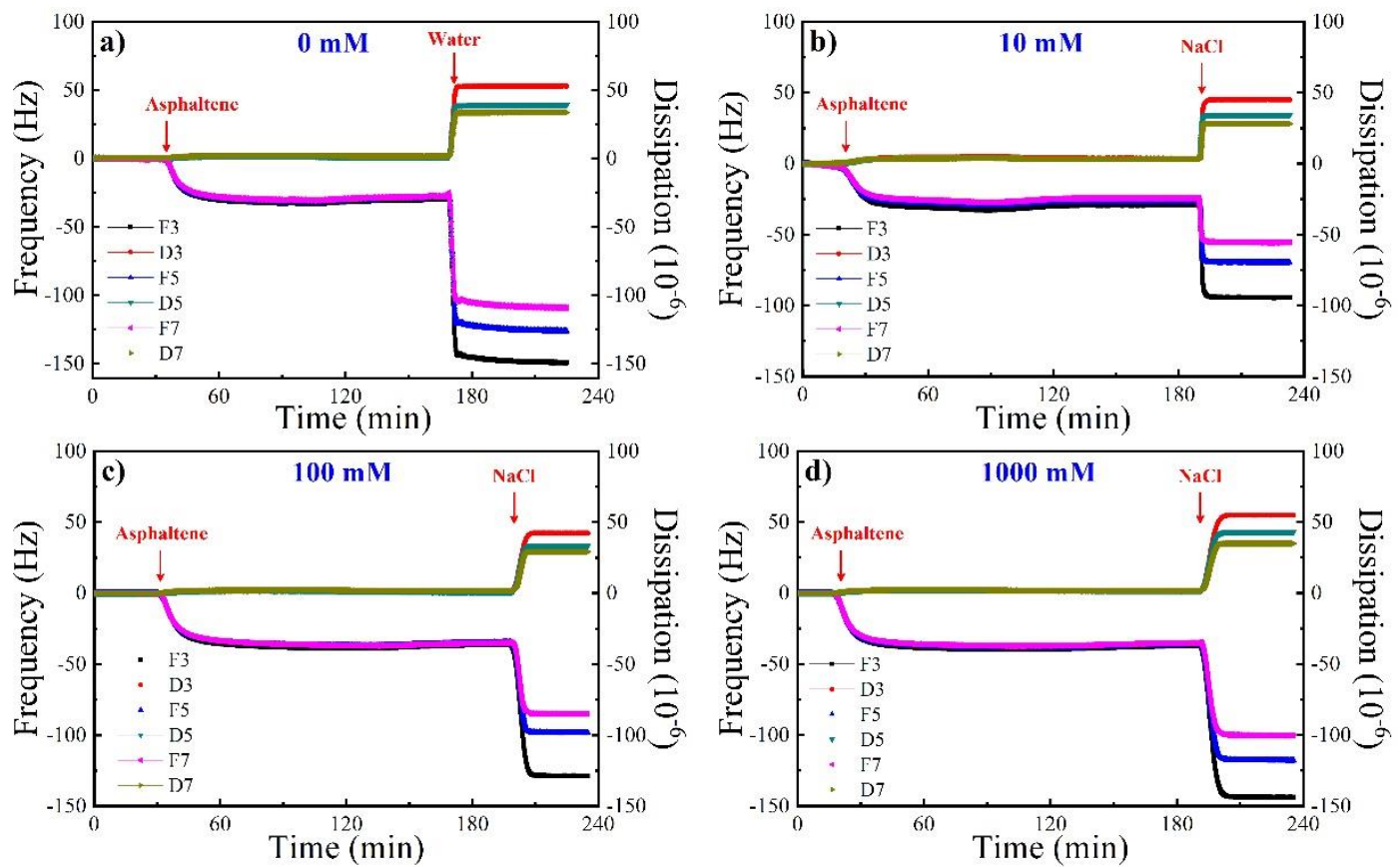

Figure 1. Frequency and dissipation shift as a function of time during asphaltene adsorption and (a) $0 \mathrm{mM}$, (b) $10 \mathrm{mM}$, (c) $100 \mathrm{mM}$, (d) $1000 \mathrm{mM} \mathrm{NaCl}$ rinsing.

With the addition of the $\mathrm{NaCl}$ solution, the frequency decreases from the range of -50 to $-90 \mathrm{~Hz}$ to -100 to $-150 \mathrm{~Hz}$ with the salinity increasing from $10 \mathrm{mM}$ to $1000 \mathrm{mM}$, whereas the dissipation has a slow rising trend around $50 \times 10^{-6}$ with increasing salinity. Compared with pure water, the frequency is higher in the presence of $10 \mathrm{mM} \mathrm{NaCl}$ than that in the pure water system, similar in the presence of $100 \mathrm{mM} \mathrm{NaCl}$ with that in the pure water system, and lower in the presence of $1000 \mathrm{mM} \mathrm{NaCl}$ than that in the pure water system (Figure 1a). These results imply that, on the premise of the same liquid loading effect in all the aqueous solutions, lowering salinity facilitates the desorption of asphaltene, suggesting that salinity has a significant impact on the asphaltene-brine-silica interaction. We speculate that this is attributed to the compaction of electrical double layer between asphaltene and quartz as a result of increasing salinity. Therefore, more asphaltene can be removed at lower concentrations of $\mathrm{NaCl}$, and after the desorption of more polar sites on the substrate would be available for water molecules, triggering a more water-wet surface.

\subsection{Effect of Salinity on Zeta Potential of Asphaltene-Brine-Silica System}

Decreasing salinity results in more negative zeta potentials for both asphaltene-brine and brine-silica interfaces, suggesting an increase of repulsive forces with decreasing salinity, thus a more water-wet system. For example, zeta potential decreases from -6.6 to $-17.1 \mathrm{mV}$ as salinity decreases from 1000 to $10 \mathrm{mM}$ for asphaltene-brine (Table 1). Similarly, zeta potential decreases from -1.5 to $-29.0 \mathrm{mV}$ as salinity declines from 1000 to $10 \mathrm{mM}$ for brine-silica (Table 1). Similar results were also reported by research groups, they claimed that zeta potential of brine-kaolinite systems decreased from -10 to $-30 \mathrm{mV}$ with decreasing salinity from 50 to $2000 \mathrm{mg} / \mathrm{L}$ of $\mathrm{NaCl}$ [25]. Likewise, zeta potential of brine-mineral and brine-oil follows the same trend as brine-kaolinite in the presence of various brines. That is, decreasing the salinity leads to more negative zeta potentials at both asphaltene-brine and brine-silica interfaces, and reduces the expansion of the electrical double layer and decreases the repulsive forces, which results in a more water-wet state and facilitates asphaltene desorption from the 
surface. This also explains why more asphaltenes can be removed from the silica surface at lower $\mathrm{NaCl}$ concentrations in the above QCM-D experiment.

Table 1. Zeta potentials at different interfaces.

\begin{tabular}{ccc}
\hline \multirow{2}{*}{ Concentration of NaCl Solution (mM) } & \multicolumn{2}{c}{ Zeta Potential (mV) } \\
& Asphaltene-Brine & Brine-Silica \\
\hline 10 & -17.1 & -29.0 \\
100 & -12.8 & -21.3 \\
1000 & -6.6 & -1.5 \\
\hline
\end{tabular}

\subsection{Effect of Salinity on Interactions of Asphaltene-Brine-Silica System}

Here, disjoining pressure was used to characterize the interaction forces in the asphaltene-brine-silica system. Positive disjoining pressure means repulsive forces between asphaltene and silica in the brine, suggesting a relatively water-wet system, whereas negative disjoining pressure means attractive forces between asphaltene and silica in the brine, implying a relatively oil-wet system [26]. Our calculations indicate that with the decrease in brine concentration, disjoining pressure changes from negative to positive, which implies that lowering salinity likely shifts an oil-wet system to a water-wet system (Figure 2a). For example, in the presence of $1000 \mathrm{mM}$ and $100 \mathrm{mM} \mathrm{NaCl}$, disjoining pressure is negative and monotonically decreases with decreasing separation distance. For $10 \mathrm{mM} \mathrm{NaCl}$, the disjoining pressure exhibits a positive value indicating the presence of repulsion. It is worth noting that the decrease in salinity triggers the outward expansion of the electrostatic double layer, resulting in an increase in electrostatic repulsion [27]. The disjoining pressure calculation reasonably explains the above zeta potential experimental results, implying that lowering salinity induces more negative zeta potential of asphaltene-brine and brine-silica interfaces, resulting in the repulsive force and water-wet system.
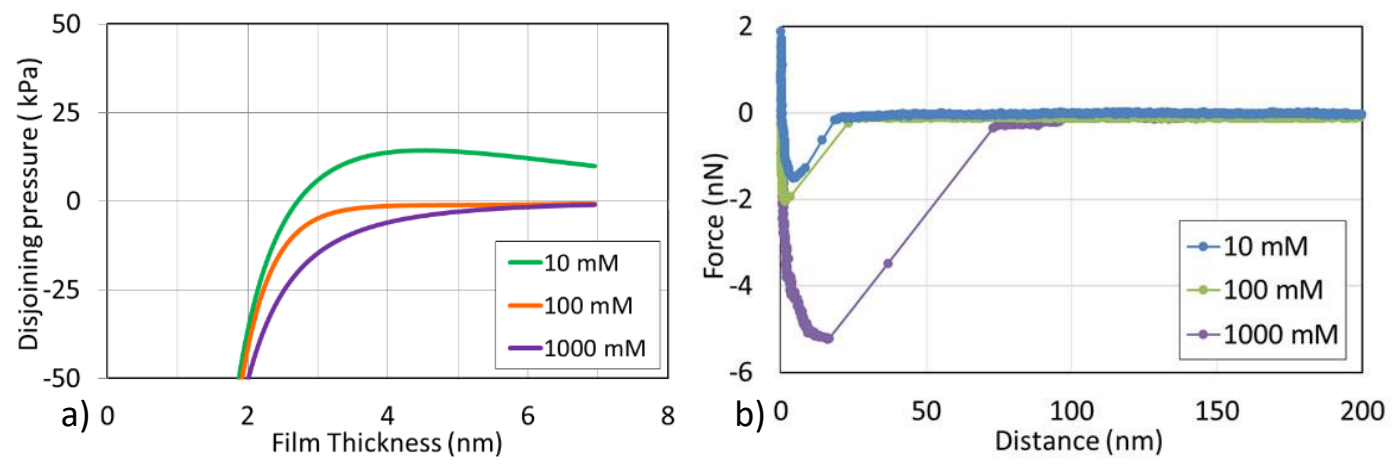

Figure 2. (a) Disjoining pressures and (b) Adhesion forces of asphaltene-brine-silica systems in the presence of various salinities.

In addition, we have directly measured the interaction between the asphaltene model compound and surfaces by the aid of a chemical force microscope (Figure $2 b$ ). The adhesion forces between asphaltene and surfaces were obtained by the max deflection on the $y$ axis from every retract force curve. For example, at a concentration of $10 \mathrm{mM}$, the adhesion force was only about $1.5 \mathrm{nN}$, and at $1000 \mathrm{mM}$, the adhesion force increased to $5.0 \mathrm{nN}$. It can be considered that the adhesion force increased as the salinity increased. These results are also in line with the calculations data of disjoining pressure (Figure 2a), showing that as the salinity decreased from 1000 to $10 \mathrm{mM}$, the adhesion forces between asphaltene and surface are significantly reduced, which is beneficial to the desorption of asphaltene from silicon surface. It is worth noting that this is also the reason for low salinity $\mathrm{NaCl}$ solution peeling off more asphaltene.

Moreover, the interaction of the asphaltene-brine-silica system is also thought to be governed by thermodynamics [26-29], which can be depicted using DLVO theory, together with electrostatics, [23,30-32], 
which can be described using surface complexation modelling. In order to understand how the surface species at asphaltene-brine and brine-silica interfaces impact the interaction of asphaltene-brine-silica system, a geochemical study was performed in the following subsection.

\subsection{Effect of Salinity/pH on Interactions of Asphaltene-Brine-Silica System}

From surface complexation modelling, it indicates that $-\mathrm{NH}^{+}$dominates asphaltene surface charges at low $\mathrm{pH}(\mathrm{pH}<6)$ in line with previous reports [33]. The number of $-\mathrm{NH}^{+}$declines with decreasing salinity as $\mathrm{pH}<6.5$, whereas the opposite trend is observed, showing that the number of $-\mathrm{NH}^{+}$increases with decreasing salinity as $\mathrm{pH}>6.5$ (Figure $3 \mathrm{a}$ ). For example, at $\mathrm{pH}=5,-\mathrm{NH}^{+}$ decreases from 14.8 to $7.2 \mu \mathrm{mol} / \mathrm{m}^{2}$ as salinity declines from 1000 to $10 \mathrm{mM}$. A similar trend has been observed before, indicating that when $\mathrm{pH}<6.5$, the number of $-\mathrm{NH}^{+}$groups increase as the ionic strength increases; when $\mathrm{pH}>6.5$ the number of $-\mathrm{NH}^{+}$groups on asphaltene surface decreases as the ionic strength increases [33]. Compared with $-\mathrm{NH}^{+}$, salinity has a minor effect on the number of $-\mathrm{COO}^{-}$at a given $\mathrm{pH}$, showing that increasing salinity decreases the number of $-\mathrm{COO}^{-}$, due to the fact that asphaltene has a low acid number $(2.75 \mathrm{mg} \mathrm{KOH} / \mathrm{g})$ but high base number $(12.34 \mathrm{mg} \mathrm{KOH} / \mathrm{g})$. For example, at $\mathrm{pH}=5$, increasing salinity from 10 to $1000 \mathrm{mM}$ decreases the number of $-\mathrm{COO}^{-}$only from 4.7 to $4.0 \mu \mathrm{mol} / \mathrm{m}^{2}$. Without adjusting the $\mathrm{pH}$ value, the numbers of $-\mathrm{NH}^{+}$and $-\mathrm{COO}^{-}$in our brine systems during the $\mathrm{pH}$ value around 6.5 are similar and, therefore, there is little effect of salinity on the number of surface species at asphaltene-brine interfaces.
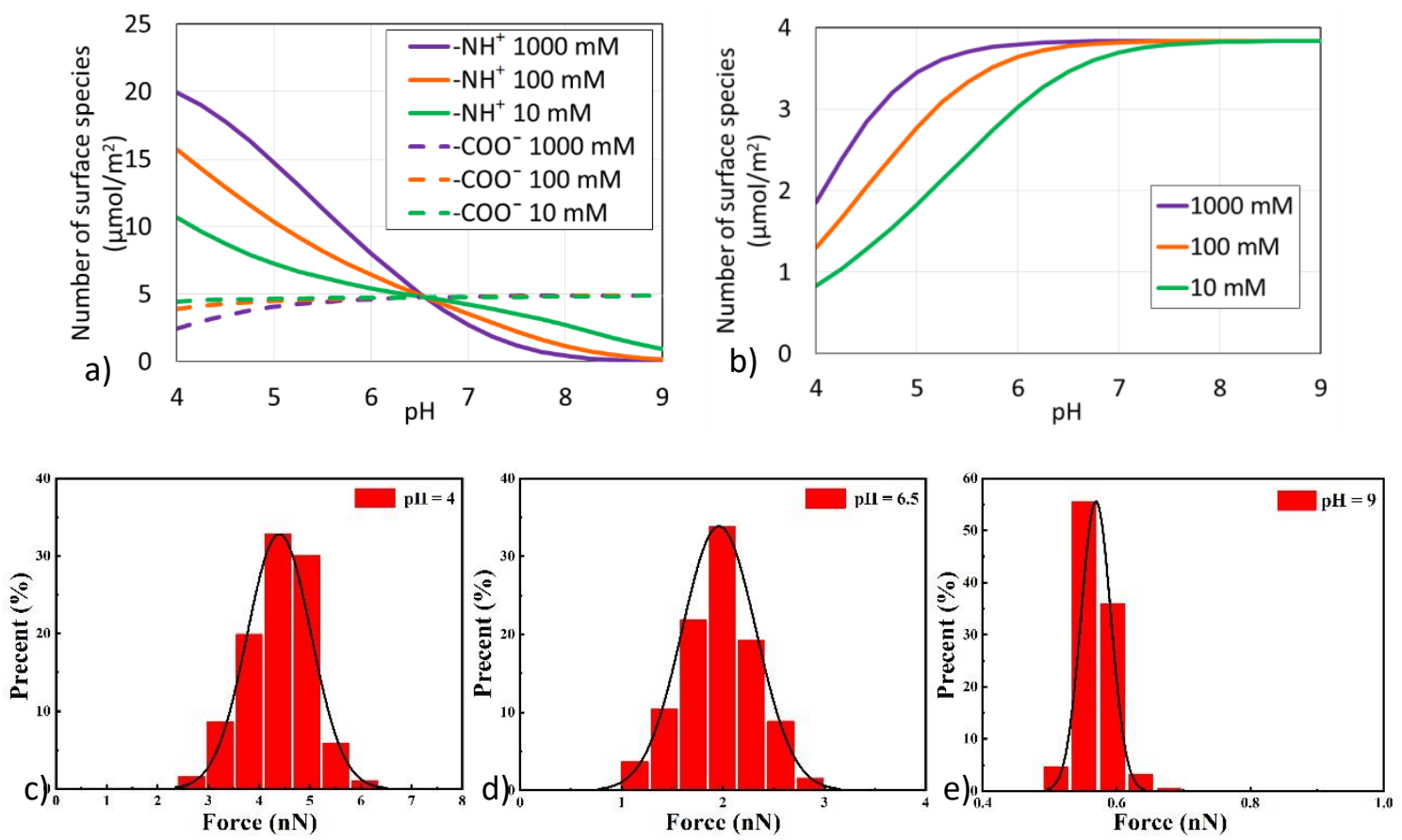

Figure 3. Effect of $\mathrm{pH}$ on (a) Number of surface species at asphaltene surfaces and (b) Number of surface species at silica surfaces in the presence of various salinities, and Adhesion forces of asphaltene-brine-silica systems in the presence of $100 \mathrm{mM} \mathrm{NaCl}$ at (c) $\mathrm{pH} 4$, (d) $\mathrm{pH}$ 6.5, and (e) $\mathrm{pH} 9$.

Increasing salinity increases the number of $>\mathrm{SiO}^{-}$at the silica surfaces at $\mathrm{pH}<7$, implying more bonds between $\mathrm{SiO}^{-}$and $-\mathrm{NH}^{+}$and resulting in a more oil-wet system. For example, at $\mathrm{pH}=5,>\mathrm{SiO}^{-}$ increases from 1.8 to $3.5 \mu \mathrm{mol} / \mathrm{m}^{2}$ (Figure $3 \mathrm{~b}$ ). It is also found that increasing $\mathrm{pH}$, in particular $\mathrm{pH}>7$, triggers a negligible effect of salinity on the number of surface species. For example, at $\mathrm{pH}=7,>\mathrm{SiO}^{-}$ increases from 3.7 to $3.8 \mu \mathrm{mol} / \mathrm{m}^{2}$ as salinity increases from 10 to $1000 \mathrm{mM}$. In our given $\mathrm{pH}$ condition around 6.5 , the number of $>\mathrm{SiO}^{-}$increases as salinity increases from 10 to $1000 \mathrm{mM}$, which may result in more $>\mathrm{SiOH}$ sites and a bigger bond product sum between asphaltene-brine and brine-silica 
interfaces. Accordingly, the attractive interactions between interfaces are likely to be enhanced with the increase of salinity, inducing more asphaltene attached to the silica surface and more oil-wet.

In order to verify the $\mathrm{pH}$ effect shown in the calculation results of the above surface complexation modelling, we measured the adhesion forces between the asphaltene model compound and silica surface at different $\mathrm{pH}$ conditions and plotted statistical graphs for easy observation. Because the effect of $\mathrm{pH}$ condition is consistent at each concentration, here only $100 \mathrm{mM} \mathrm{NaCl}$ solution was used as an example for discussion. At $\mathrm{pH}=4$, the adhesion forces between asphaltene model compound and silica surface is about $4.5 \mathrm{nN}$ (Figure 3c), indicating that asphaltene has a strong adhesion tendency to the silica surface under low $\mathrm{pH}$ conditions. When $\mathrm{pH}=6.5$, the adhesion forces decreases to around 2.0 $\mathrm{nN}$ (Figure 3d), and at $\mathrm{pH}=9$, the adhesion is almost zero (Figure 3e), showing that an increase in $\mathrm{pH}$ would weaken the adhesion forces between asphaltene and silica surface. Therefore, as the $\mathrm{pH}$ value increases, the attractive interactions between the interfaces are likely to be weakened, resulting in more asphaltenes desorbed from the silica surface and increasing the hydrophilicity of the rock surface.

\section{Materials and Methods}

\subsection{Experiments}

\subsubsection{Asphaltene Extraction and Characterization}

Given that unconventional reservoirs are rich in organic matters [34-36], and asphaltene is widely distributed at pore surfaces [37-39], asphaltene was used in this work to represent the organic matters in unconventional reservoirs. The experimental asphaltenes was extracted from oil sand (Long Lake, Ontario, Canada) as the adsorbate for quartz crystal microbalance experiments. The asphaltenes extraction process is detailed in our previous publication [17], and the main steps are shown in Figure 4.

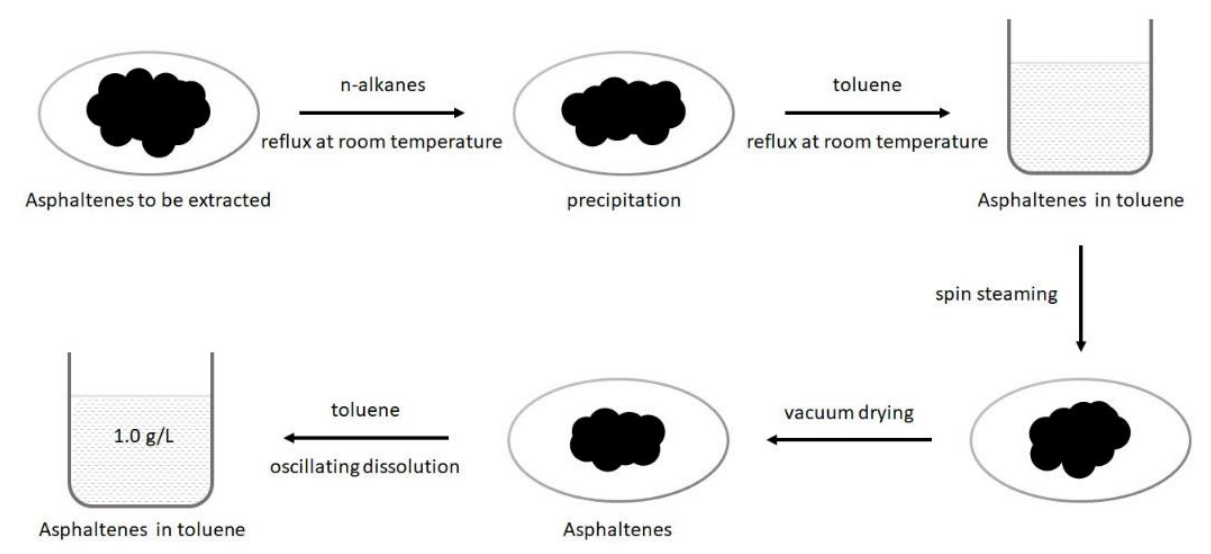

Figure 4. Schematic diagram of the asphaltenes extraction process.

\subsubsection{Brines}

$\mathrm{NaCl}$ aqueous solutions at three concentrations of 10,100 , and $1000 \mathrm{mM}$ were used in the experiments. $\mathrm{NaCl}(\mathrm{AR}, 99.5 \%)$ with Milli-Q grade water with a resistivity of $18.2 \mathrm{M} \Omega \cdot \mathrm{cm}$ at the concentration of $1000 \mathrm{mM}$ was used to deploy the experimental brines. The initial $\mathrm{pH}$ values of $10 \mathrm{mM}$, $100 \mathrm{mM}$, and $1000 \mathrm{mM} \mathrm{NaCl}$ solutions were about 7.09,6.76, and 6.13, respectively. When exploring the salinity effect, all the $\mathrm{pH}$ values of the solutions were adjusted to $6.5 \pm 0.05$ using $\mathrm{HCl}$ or $\mathrm{NaOH}$ to get rid of the $\mathrm{pH}$ effect on the adsorption of asphaltene on the silica surface. When exploring the $\mathrm{pH}$ effect, 4, 6.5, and 9 were chosen to represent acidic, neutral and alkaline solutions, respectively. All the solution preparations and $\mathrm{pH}$ adjustment operations are performed at $25^{\circ} \mathrm{C}$. 


\subsubsection{Experimental Procedure}

QCM-D (Q-SENSE E4, Biolin Scientific, Stockholm, Sweden) was used to measure the adsorption and desorption of asphaltene on silica-coated quartz crystal sensors (QSX 303, Biolin Scientific, Sweden) in the presence of various brines. In the experiment, the adsorption/desorption behavior of asphaltene on the silica surface was monitored in real time by recording the frequency and dissipation curve over time. Frequency shift is used to indicate the change in mass on the surface. A negative shift indicates that molecules are adsorbed on the surface, and a positive shift indicates that molecules are removed from the surface. Dissipation is used to characterize the softness of the adsorption layer on the surface. For example, large dissipation indicates loose molecular arrangement. Different harmonics can be collected, and in this work three of them are selected for analysis. Here we briefly described the procedures of the experiments because the principle and the detailed experimental procedures of QCM-D experiments were documented in our previous work [18]. Silica crystals' surfaces were cleaned with $5 \mathrm{wt} \%$ sodium dodecyl sulfate (SDS) solution for $60 \mathrm{~min}$, followed by thoroughly rinsing three times with ethanol (AR, 99\%) and Milli-Q water. After the acquirement of baseline in air, the experiments are divided into four steps: 1) Toluene is introduced as the background solution until the baseline is flat; 2) The asphaltene is introduced and then a significant decrease in frequency appears; 3) The background solution (toluene) is introduced again to remove the weakly bound components; 4) Brine solutions at 10, 100, and $1000 \mathrm{mM}$ were introduced respectively to measure the desorption process of asphaltenes from solid surfaces. All the adsorption/desorption experiments were executed with a constant flow rate of $50 \mu \mathrm{L} \mathrm{min}{ }^{-1}$.

Atomic force microscopy (Multimode VIII, Bruker Instruments, Santa Barbara, CA, USA) was used to measure the adhesion forces between asphaltene and silica surfaces at the molecular level. $N$-(1-hexylheptyl)- $N^{\prime}$-(5-carboxylicdodecyl) perylene-3,4,9,10-tetracarboxylic bisimide (C5Pe) was selected as a model compound to mimic asphaltene. The method of using model compounds to establish the relationship between the asphaltene molecular structure and interface properties is described in detail in our previous work [40]. The following is a brief introduction for the experimental process: 1) Functionalization tips were prepared by modifying the C5Pe molecules to gold-plated commercial atomic force microscope (AFM) tips (NPG-10, Bruker Instruments, Santa Barbara, USA); 2) silica as a substrate to simulate the surface of reservoirs; 3) the interaction between C5Pe molecules and silica surface were measured with the contact mode by AFM in different $\mathrm{NaCl}$ environments; 4) adhesion curves were repeated more than 100 times in different regions, and the normal force curves and histograms were obtained through normalization or statistics.

\subsubsection{Zeta Potential Measurements}

Zeta potentials of asphaltene-brines and silica-brines interfaces were measured using a Zetasizer Nano (Nano-ZS, Malvern, UK) following the experimental method reported in previous literature [41]. Due to the fact the quartz crystal microbalance experiments were conducted at $25^{\circ} \mathrm{C}$, all zeta potential tests were conducted at the same temperature.

\subsection{Surface Complexation Modelling}

Given that asphaltene and silica surfaces are attached surface charges, surface complexation modelling appears to be a practical approach to gain a deeper understanding of the complex interaction of asphaltene-brine-silica system (Figure 5). We therefore performed a geochemical study and compared it with DLVO theory to delineate the interplay of asphaltene-brine-silica system. The surface species concentrations were calculated using PHREEQC version 3.3.9 (United States Geological Survey) in light of the diffuse layer surface model [42]. The geochemical reactions are given in Table 2 with equilibrium constants at $298 \mathrm{~K}$. Note: in the surface complexation modelling, the acid number $2.75 \mathrm{mg}$ $\mathrm{KOH} / \mathrm{g}$ and base number, $12.34 \mathrm{mg} \mathrm{KOH} / \mathrm{g}$, were used as referring to the literature $[33,43]$. 


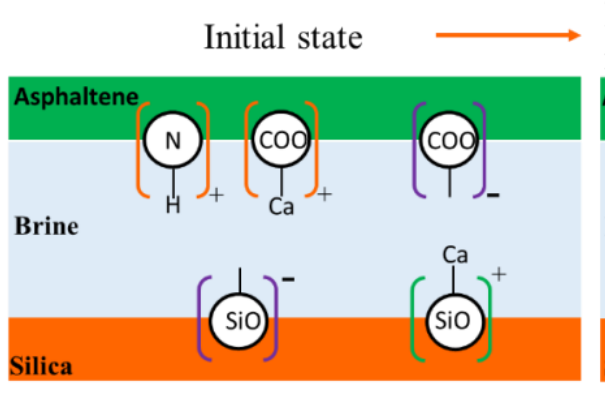

Both salinity and $\mathrm{pH}$ control the number of surface species.

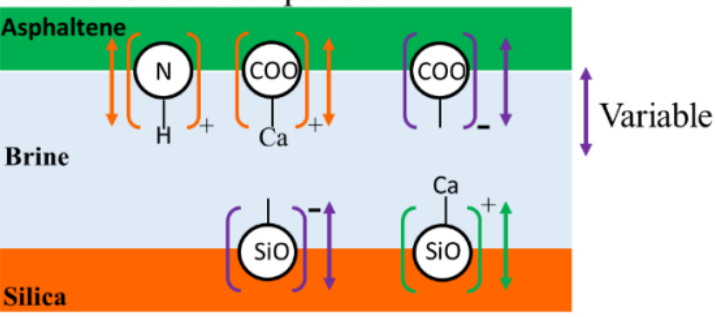

Figure 5. Schematic diagram of surface species in asphaltene-brine-silica system.

Table 2. Surface complexation modelling parameters [44].

\begin{tabular}{ccc}
\hline \multicolumn{2}{c}{ Geochemical Reactions } & $\log \mathrm{K}_{\mathbf{2 9 8 K}}$ \\
\hline \multirow{2}{*}{ Asphaltene surface } & $-\mathrm{NH}^{+}=-\mathrm{N}+\mathrm{H}^{+}$ & -6.0 \\
& $-\mathrm{COOH}=-\mathrm{COO}^{-}+\mathrm{H}^{+}$ & -5.0 \\
\hline Silica surface & $>\mathrm{SiOH}=>\mathrm{SiO}^{-}+\mathrm{H}^{+}$ & $-4.0[44]$ \\
\hline
\end{tabular}

Note: As shown in Table 2, the "-" in - $\mathrm{NH}^{+}$or - $\mathrm{COOH}$ represents the groups present at the asphaltene-brine interface [23], and " $>$ " in $>\mathrm{SiOH}$ represents the groups present at the silica-brine interface [30,45].

\section{Implications and Conclusions}

The low recovery of hydraulic fracturing fluid in unconventional reservoirs, such as tight sandstone, shale oil, and gas reservoirs, has received extensive attention both in terms of technology and environment in the last decade [3]. While a variety of mechanisms have been developed to understand why and how the fracturing fluids disappear, how the water chemistry affects the asphaltene-brine-silica system interplay and the surface wettability has received little attention at a molecular level. Here, the adsorption/desorption behavior and interaction forces of asphaltenes on the silica surface in the presence of different concentrations of $\mathrm{NaCl}$ were measured by QCM-D and CFM, respectively. Furthermore, we combined DLVO theory and surface complexation modelling to delineate the experimental results.

Our results showed that with the injection of water, there is a strong water uptake and the asphaltene adlayers become swelling, which may be one of the big challenges in tight sandstone reservoirs. Lowering salinity increases the asphaltene desorption and triggers a strongly negative zeta potential of both asphaltene-brine and brine-silica interfaces, implying a more water-wet system. We found that DLVO theory supports the experimental results, showing that decreasing salinity or increasing the $\mathrm{pH}$ value gives a bigger repulsive force which is confirmed by disjoining pressure calculation in this study and previous work. Surface complexation modelling further explains the increase of asphaltene desorption with decreasing salinity or increasing $\mathrm{pH}$, which is attributed to less $-\mathrm{NH}^{+}$sites at asphaltene-brine interfaces and lower number of bonds between asphaltene-brine and brine-silica interfaces. We conclude that hydraulic fracturing fluid increases the water-wetness, in favor of water uptake, while low salinity or high $\mathrm{pH}$ water facilitates the asphaltene desorption and inhibits the electrical double layer swelling, which in turn likely improves the water flowback in various applications.

Author Contributions: H.Y. and Q.X. conceived the experiments. F.L. performed the AFM measurements and wrote the manuscript. T.C., S.Z., D.Y., and Y.C. participated in the materials preparation and characterization. All authors were involved in analyzing the results and revising the manuscript. All authors have read and agreed to the published version of the manuscript.

Funding: This work was supported by the National Natural Science Foundation of China (21872152 and 21603240), the Important National Science and Technology Specific Project of China (2017ZX05013-003), and the Strategic Priority Research Program of CAS (XDB22030102).

Conflicts of Interest: The authors declare no conflicts of interest. 


\section{References}

1. Gregory, K.B.; Vidic, R.D.; Dzombak, D.A. Water Management Challenges Associated with the Production of Shale Gas by Hydraulic Fracturing. Elements 2011, 7, 181-186. [CrossRef]

2. Gadonneix, P.; Sambo, A.; Guobao, Z.; Kim, Y.D.; Teyssen, J.; Lleras, J.A.V.; Naqi, A.A.; Meyers, K.; Shin, H.C.; Nadeau, M.-J.; et al. World Energy Issues Monitor; World Energy Council: London, UK, 2012.

3. Roshan, H.; Al-Yaseri, A.Z.; Sarmadivaleh, M.; Iglauer, S. On Wettability of Shale Rocks. J. Colloid. Interf. Sci. 2016, 475, 104-111. [CrossRef]

4. Zhou, Z.; Abass, H.; Li, X.; Bearinger, D.; Frank, W. Mechanisms of Imbibition during Hydraulic Fracturing in Shale Formations. J. Petrol. Sci. Eng. 2016, 141, 125-132. [CrossRef]

5. Dehghanpour, H.; Zubair, H.A.; Chhabra, A.; Ullah, A. Liquid Intake of Organic Shales. Energy Fuel. 2012, 26, 5750-5758. [CrossRef]

6. Ghanbari, E.; Dehghanpour, H. Impact of Rock Fabric on Water Imbibition and Salt Diffusion in Gas Shales. INT. J. COAL. GEOL. 2015, 138, 55-67. [CrossRef]

7. Dehghanpour, H.; Lan, Q.; Saeed, Y.; Fei, H.; Qi, Z. Spontaneous Imbibition of Brine and Oil in Gas Shales: Effect of Water Adsorption and Resulting Microfractures. Energy Fuel. 2013, 27, 3039-3049. [CrossRef]

8. Makhanov, K.; Habibi, A.; Dehghanpour, H.; Kuru, E. Liquid Uptake of Gas Shales: A Workflow to Estimate Water Loss During Shut-in Periods after Fracturing Operations. J. UNCONV. OIL GAS RESOUR. 2014, 7, 22-32. [CrossRef]

9. Binazadeh, M.; Xu, M.; Zolfaghari, A.; Dehghanpour, H. Effect of Electrostatic Interactions on Water Uptake of Gas Shales: The Interplay of Solution Ionic Strength and Electrostatic Double Layer. Energy Fuel. 2016, 30, 992-1001. [CrossRef]

10. Roshan, H.; Ehsani, S.; Marjo, C.E.; Andersen, M.S.; Acworth, R.I. Mechanisms of Water Adsorption into Partially Saturated Fractured Shales: An Experimental Study. Fuel 2015, 159, 628-637. [CrossRef]

11. Fakcharoenphol, P.; Kurtoglu, B.; Kazemi, H.; Charoenwongsa, S.; Wu, Y.S. The Effect of Osmotic Pressure on Improve Oil Recovery from Fractured Shale Formations. In Proceedings of the SPE Unconventional Resources Conference, The Woodlands, TX, USA, 1-3 April 2014.

12. Zhou, Z.; Abass, H.; Li, X.; Teklu, T. Experimental Investigation of the Effect of Imbibition on Shale Permeability during Hydraulic Fracturing. J. Nat. Gas Sci. Eng. 2016, 29, 413-430. [CrossRef]

13. Al-Hadhrami, H.S.; Blunt, M.J. Thermally Induced Wettability Alteration to Improve Oil Recovery in Fractured Reservoirs. Spe. Reserv. Eval. Eng. 2001, 4, 179-186. [CrossRef]

14. Schembre, J.M.; Tang, G.Q.; Kovscek, A.R. Wettability Alteration and Oil Recovery by Water Imbibition at Elevated Temperatures. J. Petrol. Sci. Eng. 2006, 52, 131-148. [CrossRef]

15. Kathel, P.; Mohanty, K.K. EOR in Tight Oil Reservoirs through Wettability Alteration. In Proceedings of the SPE Annual Technical Conference and Exhibition, New Orleans, LA, USA, 30 September-2 October 2013.

16. Siddiqui, M.A.Q.; Chen, X.; Iglauer, S.; Roshan, H. A Multiscale Study on Shale Wettability: Spontaneous Imbibition Versus Contact Angle. Water Resour. Res. 2019, 55, 5012-5032. [CrossRef]

17. Strand, S.; Høgnesen, E.J.; Austad, T. Wettability Alteration of Carbonates-Effects of Potential Determining Ions $\left(\mathrm{Ca}^{2+}\right.$ and $\left.\mathrm{SO}_{4}{ }^{2-}\right)$ and Temperature. Colloid. Surf. A Physicochem. Eng. Asp. 2006, 275, 1-10. [CrossRef]

18. Yang, G.; Chen, T.; Zhao, J.; Yu, D.; Liu, F.; Wang, D.; Fan, M.; Chen, W.; Zhang, J.; Yang, H.; et al. Desorption Mechanism of Asphaltenes in the Presence of Electrolyte and the Extended Derjaguin-Landau-Verwey-Overbeek Theory. Energy Fuel. 2015, 29, 4272-4280. [CrossRef]

19. Liang, T.; Zhou, F.; Lu, J.; DiCarlo, D.; Nguyen, Q. Evaluation of Wettability Alteration and IFT Reduction on Mitigating Water Blocking for Low-permeability Oil-wet Rocks after Hydraulic Fracturing. Fuel 2017, 209, 650-660. [CrossRef]

20. Lashkarbolooki, M.; Ayatollahi, S.; Riazi, M. The Impacts of Aqueous Ions on Interfacial Tension and Wettability of an Asphaltenic-Acidic Crude Oil Reservoir during Smart Water Injection. J. Chem. Eng. Data 2014, 59, 3624-3634.21. [CrossRef]

21. Dunlop, I.E.; Thomas, R.K.; Titmus, S.; Osborne, V.; Edmondson, S.; Huck, W.T.S.; Klein, J. Structure and Collapse of a Surface-Grown Strong Polyelectrolyte Brush on Sapphire. Langmuir 2012, 28, 3187-3193. [CrossRef]

22. Rodahl, M.; Kasemo, B. On the Measurement of Thin Liquid Overlayers with the Quartz-Crystal Microbalance. Sensor. Actuat. A-Phys. 1996, 54, 448-456. [CrossRef] 
23. Brady, P.V.; Krumhansl, J.L. A Surface Complexation Model of Oil-Brine-Sandstone Interfaces at $100{ }^{\circ} \mathrm{C}$ : Low Salinity Waterflooding. J. Petrol. Sci. Eng. 2012, 81, 171-176. [CrossRef]

24. Chen, T.; Liu, F.; Huang, S.; Zhang, W.; Wang, H.; Hou, Q.; Guo, D.; Ma, A.; Sun, K.; Yang, H.; et al. "Peeling Off" Mechanism of Asphaltenes from Solid/Liquid Interface in the Presence of a Highly Charged Amphiphilic Macromolecule. Energy Fuel. 2016, 30, 9250-9259. [CrossRef]

25. Nasralla, R.A.; Nasr-El-Din, H.A. Impact of Cation Type and Concentration in Injected Brine on Oil Recovery in Sandstone Reservoirs. J. Petrol. Sci. Eng. 2014, 122, 384-395. [CrossRef]

26. Hirasaki, G.J. Wettability: Fundamentals and Surface Forces. SPE Form. Evaluation. 1991, 6, $217-226$. [CrossRef]

27. Xie, Q.; Saeedi, A.; Pooryousefy, E.; Liu, Y. Extended DLVO-Based Estimates of Surface Force in Low Salinity Water Flooding. J. Mol. Liq. 2016, 221, 658-665. [CrossRef]

28. Buckley, J.S.; Morrow, N.R. Characterization of Crude Oil Wetting Behavior by Adhesion Tests. In Proceedings of the SPE/DOE Enhanced Oil Recovery Symposium, Tulsa, OK, USA, 22-25 April 1990.

29. Nasralla, R.A.; Nasr-El-Din, H.A. Impact of Electrical Surface Charges and Cation Exchange on Oil Recovery by Low Salinity Water. In Proceedings of the SPE Asia Pacific Oil and Gas Conference and Exhibition, Jakarta, Indonesia, 20-22 September 2011.

30. Brady, P.V.; Bryan, C.R.; Thyne, G.; Li, H. Altering Wettability to Recover More Oil from Tight Formations. J. Unconv. Oil Gas Resour. 2016, 15, 79-83. [CrossRef]

31. Xie, Q.; Brady, P.V.; Pooryousefy, E.; Zhou, D.; Liu, Y.; Saeedi, A. The Low Salinity Effect at High Temperatures. Fuel 2017, 200, 419-426. [CrossRef]

32. Chen, Y.; Xie, Q.; Sari, A.; Brady, P.V.; Saeedi, A. Oil/Water/Rock Wettability: Influencing Factors and Implications for Low Salinity Water Flooding in Carbonate Reservoirs. Fuel 2018, 215, 171-177. [CrossRef]

33. Brady, P.V.; Morrow, N.R.; Fogden, A.; Deniz, V.; Loahardjo, N. Electrostatics and the Low Salinity Effect in Sandstone Reservoirs. Energy Fuel. 2015, 29, 666-677. [CrossRef]

34. Kuila, U.; McCarty, D.K.; Derkowski, A.; Fischer, T.B.; Topór, T.; Prasad, M. Nano-scale Texture and Porosity of Organic Matter and Clay Minerals in Organic-rich Mudrocks. Fuel 2014, 135, 359-373. [CrossRef]

35. Sanei, H.; Wood, J.M.; Ardakani, O.H.; Clarkson, C.R.; Jiang, C. Characterization of Organic Matter Fractions in an Unconventional Tight Gas Siltstone Reservoir. Int. J. Coal Geol. 2015, 150, 296-305. [CrossRef]

36. Ma, Y.Z.; Moore, W.; Gomez, E.; Luneau, B.; Kaufman, P.; Gurpinar, O.; Handwerger, D. Chapter 5 -Wireline Log Signatures of Organic Matter and Lithofacies Classifications for Shale and Tight Carbonate Reservoirs. In Book Unconventional Oil and Gas Resources Handbook; Ma, Y.Z., Holditch, S.A., Eds.; Gulf Professional Publishing: Boston, MA, USA, 2016; pp. 151-171.

37. Papadimitriou, N.; Romanos, G.; Charalambopoulou, G.C.; Kainourgiakis, M.; Katsaros, F.; Stubos, A. Experimental Investigation of Asphaltene Deposition Mechanism during Oil Flow in Core Samples. J. Petrol. Sci. Eng. 2007, 57, 281-293. [CrossRef]

38. Sayyouh, M.; Hemeida, A.; Al-Blehed, M.; Desouky, S. Role of Polar Compounds in Crude Oils on Rock Wettability. J. Petrol. Sci. Eng. 1991, 6, 225-233. [CrossRef]

39. Tong, Z.; Morrow, N.; Xie, X. Spontaneous Imbibition for Mixed-wettability States in Sandstones Induced by Adsorption from Crude Oil. J. Petrol. Sci. Eng. 2003, 39, 351-361. [CrossRef]

40. Liu, F.; Yang, H.; Wang, J.; Qian, Y.; Wu, J.; Li, S.; Liu, Q.; Yang, S.; Xu, S.; Zhang, X.; et al. Molecular Interaction between Asphaltene and Quartz with Different Surface Wettability: A Combined Study of Experimental Measurement and Theoretical Calculation. Fuels 2019, 258, 115937. [CrossRef]

41. Xie, Q.; Liu, Y.; Wu, J.; Liu, Q. Ions Tuning Water Flooding Experiments and Interpretation by Thermodynamics of Wettability. J. Petrol. Sci. Eng. 2014, 124, 350-358. [CrossRef]

42. Parkhurst, D.L.; Appelo, C. Description of Input and Examples for PHREEQC Version 3: A Computer Program for Speciation, Batch-Reaction, One-Dimensional Transport, and Inverse Geochemical Calculations; US Geological Survey: Reston, VA, USA, 2013; pp. 2328-7055.

43. Hosseinpour, N.; Khodadadi, A.A.; Bahramian, A.; Mortazavi, Y. Asphaltene Adsorption onto Acidic/Basic Metal Oxide Nanoparticles toward in Situ Upgrading of Reservoir Oils by Nanotechnology. Langmuir 2013, 29, 14135-14146. [CrossRef] 
44. Buckley, J.S.; Takamura, K.; Morrow, N.R. Influence of Electrical Surface Charges on the Wetting Properties of Crude Oils. SPE Reserv. Eng. 1989, 4, 332-340. [CrossRef]

45. Brady, P.V.; Krumhansl, J.L. Surface Complexation Modeling for Waterflooding of Sandstones. SPE J. 2013, 18, 214-218. [CrossRef]

Sample Availability: Samples of the compounds C5Pe are available from the authors.

(C) 2020 by the authors. Licensee MDPI, Basel, Switzerland. This article is an open access article distributed under the terms and conditions of the Creative Commons Attribution (CC BY) license (http://creativecommons.org/licenses/by/4.0/). 